\title{
Complications of gynaecologic laparoscopy: an audit
}

\author{
Shraddha S. Shastri, Anvita A. Singh, Sameer P. Darawade*, Saloni D. Manwani
}

Department of Obstetrics and Gynecology, Smt. Kashibai Navale Medical College and General Hospital, Narhe, Pune, Maharashtra, India

Received: 14 November 2018

Accepted: 22 November 2018

\section{* Correspondence:}

Dr. Sameer P. Darawade,

E-mail: sameerpdarawade@gmail.com

Copyright: () the author(s), publisher and licensee Medip Academy. This is an open-access article distributed under the terms of the Creative Commons Attribution Non-Commercial License, which permits unrestricted non-commercial use, distribution, and reproduction in any medium, provided the original work is properly cited.

\section{ABSTRACT}

Background: Minimal access surgery as a modality of treatment for various gynecologic conditions is rapidly gaining grounds in the recent years1. Approximately 30 years after its introduction; the use of laparoscopy in gynecology has evolved from diagnostic purposes into a more coordinated system for the repair or removal of diseased abdominal and pelvic organs. The rapid increase in the number of procedures being performed, the introduction of new equipment, and variability in the training of surgeons all contribute to the complication rate. The objective is to review complications associated with laparoscopic gynecological surgeries and identify associated risk factors.

Methods: Hospital based descriptive observational study performed between January 2013 to December 2017 which included all gynecologic laparoscopies performed in present institute. Variables were recorded for patient characteristics, indication for surgery, length of hospital stay (in days), major and minor complications, conversions to laparotomy and postoperative complications. The laparoscopic procedures were divided into three subgroups: Diagnostic cases, tubal sterilization and Advanced operative laparoscopy.

Results: Of all 3724 laparoscopies included, overall frequency of major was $1.96 \%$, and that of minor complications was $3.51 \%$. Of 3724 laparoscopic procedures, 214 complications occurred (5.8\% of all procedures) and one death occurred. The level of technical difficulty and existence of prior abdominal surgery were associated with a higher risk of major complications and conversions to laparotomy.

Conclusions: Laparoscopic surgery has many advantages, but it is not without complications. Despite rapidly improving technical equipment's and surgical skill; complication rates and preventable injuries demonstrate continuous pattern. Delayed recognition and intervention add to morbidity and mortality. Each laparoscopic surgeon should be aware of the potential complications, how they can be prevented and managed efficiently.

Keywords: Complications, Gynecological laparoscopy, Outcomes, Risk factors

\section{INTRODUCTION}

Minimal access surgery as a modality of treatment for various gynecologic conditions is rapidly gaining grounds in the recent years. ${ }^{1}$ Approximately 30 years after its introduction; the use of laparoscopy in gynecology has evolved from diagnostic purposes into a more coordinated system for the repair or removal of diseased abdominal and pelvic organs. During the past decade, laparoscopic surgery was shown to have a high benefit for many reasons, for the cosmetic purposes, lesser postoperative pain, intraoperative blood loss, intraabdominal adhesion and shorter recovery period compared to conventional surgery. ${ }^{2-4}$ As the technology has improved and surgical skills have increased, the nature and characteristics of laparoscopic procedures have also become more complex. ${ }^{5}$ At centers equipped for advanced laparoscopic surgery, procedures such as 
surgery for complex adnexal lesions, hysterectomies, pelvic floor repair, and resection for severe endometriosis are now performed by this approach. ${ }^{6}$

The rapid increase in the number of procedures being performed, the introduction of new equipment, and variability in the training of surgeons all contribute to the complication rate. The more experience a surgeon has, the lower the complication rate. Although the incidence of complications decreases as surgeons gain experience with laparoscopy, the growing difficulty of some procedures in gynecology surgery may increase the frequency of severe complications. ${ }^{7-9}$ According to published studies, the overall rate of laparoscopic complications ranges from $0.4 \%$ to $3 \% .^{6,10-12}$ Complications can be classified as major or minor: the former involve the viscera (intestine, bladder, or ureter) or great vessels (including severe hemorrhage), whereas minor complications generally have a relatively low impact on the patient's postoperative course. ${ }^{13}$ Only 1 study has appeared on the complications of laparoscopic surgery in a large series of patients in Spain. ${ }^{14}$

The aim of this study was to describe the prevalence and types of gynecological laparoscopic complications based on the diagnostic and operative laparoscopies that were performed.

\section{METHODS}

The present retrospective study was based on review of medical records in Smt. Kashibai Nawale Medical College and Hospital, Pune between January 2013 to December 2018. It is a tertiary regional teaching hospital with 730 beds. The medical records of 3724 subjects who underwent gynecological laparoscopy in hospital were reviewed and analyzed. The collected data composed of demographic data, medical data, operative data, complications and treatment, and postoperative assessment. All cases were supervised by expert gynecological laparoscopists with more than 8 years of experience.

The laparoscopic procedures were divided into three subgroups: diagnostic cases, tubal sterilization and Advanced operative laparoscopy (adhesiolysis, treatment of endometriosis, ovarian cystectomy and oophorectomy salpingectomy, hysterectomy, repair of pelvic organ prolapse, tubal reanastomosis, myomectomy, radical hysterectomy and lymphadenectomy). All cases were followed up at least six weeks after surgery. If complications occurred, then additional follow up was performed and the result followed. They were reviewed in detail, and perioperative complications, correction and follow up were noted. Postoperative outcomes were also summarized from the medical file. Immediate postoperative adverse events were recorded, as was follow up until complete resolution of the complication. This is a descriptive, retrospective study. Ethics committee approval was not needed.
Operative techniques: At present institute primary port is introduced by periumbilical incision by open umbilical tube technique. Intraperitoneal insufflation was performed with an intraabdominal pressure $<15 \mathrm{mmHg}$. After adequate pressure is achieved; other secondary trocars are introduced under direct visualization.

Complications from laparoscopy were classified as major and minor. The former group of intraoperative complications included injury to the hollow organs of the viscera (intestine, bladder, or ureter) and bleeding or infection during laparoscopy or the postoperative period requiring additional intervention by laparoscopy or laparotomy. The complications which were taken into consideration were port site complications, mesosalpinx injury, hemorrhage, visceral injuries, abdominal wall vessels injury, large retroperitoneal injury, postoperative complications

\section{RESULTS}

Between January 2013 and December 2017, a total of 3724 laparoscopic surgeries were performed at present center.

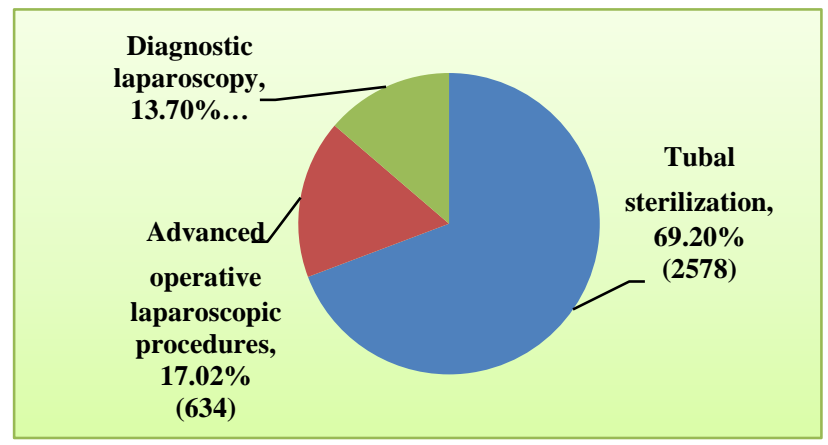

Figure 1: Total number of gynecological laparoscopic procedures.

A total of 3724 gynecological laparoscopic procedures were enrolled in study.



Figure 2: Total number of advanced laparoscopic cases over 5 years. 
The procedures included $512(13.74 \%)$ diagnostic cases; $2578(69.24 \%)$ sterilization procedures and $634(17.02 \%)$ major operative cases (advanced laparoscopic procedures).

The major operative cases which were performed were laparoscopic vaginal hysterectomy (LAVH), Total laparoscopic hysterectomy (TLH), ovarian cystectomy, myomectomy, tubal reanastomosis, laparoscopic radical hysterectomy and salpingectomy.

Figure 2 shows the types of major operative laparoscopic procedures performed at present institute which includes TLH (335), LAVH (109), Cystectomy (126), Salpingectomy (46), Myomectomy (15), laparoscopic Wertheim's hysterectomy (1) and tubal reanastomosis (2).

Table 1: Patient variables and characteristics.

\begin{tabular}{|c|c|}
\hline $\begin{array}{l}\text { Patient's characteristics of } \\
\text { gynecological laparoscopy }\end{array}$ & Data \\
\hline \multicolumn{2}{|l|}{ Age group } \\
\hline$<30$ years & 2106 \\
\hline $30-60$ years & 1554 \\
\hline$>60$ years & 64 \\
\hline Prior abdominal surgeries & 246 \\
\hline \multicolumn{2}{|l|}{ Length of hospital stay } \\
\hline $0-2$ days & 2870 \\
\hline 3-7 days & 680 \\
\hline$>7$ days & 174 \\
\hline Prolonged surgeries (>4 hours) & 16 \\
\hline
\end{tabular}

Complications from laparoscopy were classified as major and minor. The former group of intraoperative complications included injury to the hollow organs of the viscera (intestine, bladder, or ureter) and bleeding or infection during laparoscopy or the postoperative period requiring additional intervention by laparoscopy or laparotomy. The medical records of 3724 subjects who underwent gynecological laparoscopy in hospital were reviewed and analyzed. The collected data composed of demographic data, medical data, operative data, complications and treatment, and postoperative assessment. Deaths and severe medical pathologies that occurred during the postoperative period were also considered major complications.

The following variables for patients' characteristics were recorded: age, prior abdominal surgery, lengths of hospital stay (in days) and prolonged surgeries (time duration more than 4 hours (Table 1). Age was classified into 3 categories: <30 years, 30 to 60 years, and $>60$ years. Length of hospital stay was classified into 3 categories: <2 days, 2-7 days and more than 7 days. In diagnostic groups 12 complications occurred (3.22 per $1000)$ as compared to $121(33.2$ per 1000) in tubal sterilization group. 214 overall complications were recorded during study which accounts for $5.8 \%$ among all procedures. 84 complications were caused by trainees and 126 by accredited gynecologists.

Table 2: Incidence of the different types of complication which occurred during diagnostic and tubal sterilization procedures $(n=3724)$.

\begin{tabular}{|lll|}
\hline Complications & Number & Rate (\%) \\
\hline Diagnostic laparoscopy & 12 & 0.32 \\
\hline Uterine perforation & 3 & 0.08 \\
\hline Converted to laparotomy & 3 & 0.08 \\
\hline Hemorrhage & 5 & 0.13 \\
\hline Port site complication & 1 & 0.02 \\
\hline Tubal sterilization & & \\
\hline Mesosalpinx bleeding & 106 & 2.84 \\
\hline Port site complications & 10 & 0.26 \\
\hline Difficult entry & 4 & 0.1 \\
\hline Abscess & 2 & 0.05 \\
\hline Dehiscence & 3 & 0.08 \\
\hline Hernia & 1 & 0.02 \\
\hline Hemorrhage (epigastric vein) & 3 & 0.08 \\
\hline Omental injury & 1 & 0.02 \\
\hline Uterine perforation & 1 & 0.02 \\
\hline Total & 133 & 3.54 \\
\hline
\end{tabular}

2578 consecutive patients who had tubal sterilization were recruited in the study. Minor complication rate was $3.66 \%$. The most frequently observed complications were hemorrhage from mesosalpinx in 106 cases $(2.84 \%)$ which were mostly performed by trainees followed by port site complications. The most frequent complications were mesosalpingeal and mesoovarian bleeding which were controlled with bipolar electrical cauterization or reapplication of the second ring. Three minor inferior epigastric vein injury occurred due to a lower lateral 5$\mathrm{mm}$ trocar characterized by dribbling of blood from port site. Intraoperative coagulation was accomplished with an uneventful recovery after 2 postoperative hospital days. In one case, a minimal omental bleeding was observed but it did not need any further intervention.

During laparoscopic approach 5 complications were caused by insertion of trocar. In one case there was omental injury caused by insertion of probe. In 1 case the complication required laparotomy due to uterine perforation with haemorrhage. Laparotomy was not required for the completion of sterilization in any patient except for the one patient. The complications were handled efficiently using the endoscopic technique.

In the present study, the major complication rate was $1.96 \%$. The injury to urinary bladder $(0.13 \%)$ and bowel was $(0.08 \%)$ respectively. There was only one case of vesicovaginal fistula at $(0.02 \%)$. Ureteric injury rate was $(0.05 \%) .2$ ureteric injury cases were TLH cases and were found at the distal part of ureter. All cases were detected postoperatively at $2 \mathrm{nd}$ week of operation. Double $\mathrm{J}$ stent placing was done and retained until six and seven months respectively. 
All bowel injuries were found intraoperatively. There were two large bowel injury cases one at sigmoid colon and one was serosal tear of the rectum at middle part. The immediate primary suture was performed via exploratory laparotomy. In injury to sigmoid colon patient received ileostomy and tube colostomy for first repair procedure followed by prolonged hospitalization (60days) with serious complications which resulted later in death due to sepsis.

There were 5 bladder injuries diagnosed intraoperatively. There were dense adhesions to the urinary bladder and vagina because of previous cesarean section or fibrosis. The injury was recognized during surgery by visualizing bladder mucosa, Foley's balloon and spillage of instilled into urinary bladder. The diagnosis was confirmed by instillation of methylene blue dye via Foley's catheter. They were successfully repaired with vicryl no.3.0 either vaginally or by laparotomy according to operator's preference. Only 1 of these 5 patients developed vesicovaginal fistula which was detected on 13th day after operation for which fistulectomy was done. Remaining patients recovered uneventfully with Foley's catheter ins itu for 14 days.

30 patients had intraoperative hemorrhage for which 8 patients were given blood transfusion intraoperatively and 10 patients postoperatively .14 were converted to laparotomy due to massive hemorrhage. Overall conversion rate to laparotomy was $0.86 \%$. In addition; authors found that patients with prior abdominal surgery were twice as likely to have major complications compared with patients without this antecedent. The difference between patients can be explained by the presence of abdominal and pelvic adhesions that make surgery more difficult.

Table 3: Incidence of complications during major operative laparoscopy surgeries $(\mathrm{n}=3724)$.

\begin{tabular}{|c|c|c|c|c|c|}
\hline Major complications & Number & $\%$ & Type of surgery & Diagnosis & Interventions \\
\hline Bladder injury & 5 & 0.13 & TLH & Intraoperatively & Laparotomy \\
\hline Ureteric injury & 2 & 0.05 & TLH & Postoperatively & Double $\mathrm{J}$ stent insertion \\
\hline $\begin{array}{l}\text { Bowel injury } \\
\text { Rectosigmoid } \\
\text { Ileum } \\
\text { Sigmoid }\end{array}$ & 3 & 0.08 & TLH & Intraoperative & $\begin{array}{l}\text { Laparotomy, ileostomy, } \\
\text { colostomy }\end{array}$ \\
\hline Vesicovaginal fistula & 1 & 0.02 & TLH & Postoperative & Fistulectomy vaginally \\
\hline Hemorrhage & 30 & 0.8 & $\begin{array}{l}\text { TLH/ LAVH/ } \\
\text { Myomectomy/ } \\
\text { Salpingectomy }\end{array}$ & Intraoperative & \multirow{4}{*}{$\begin{array}{l}\text { Blood transfusion } \\
\text { Laparotomy } \\
\text { Procedure abandoned }\end{array}$} \\
\hline $\begin{array}{l}\text { Conversion to } \\
\text { laparotomy }\end{array}$ & 32 & 0.86 & $\begin{array}{l}\text { TLH/ LAVH/ } \\
\text { Myomectomy/ } \\
\text { Salpingectomy }\end{array}$ & & \\
\hline Death & 1 & 0.02 & TLH (Bowel injury) & Postoperative & \\
\hline Total & 74 & $1.96 \%$ & & & \\
\hline
\end{tabular}

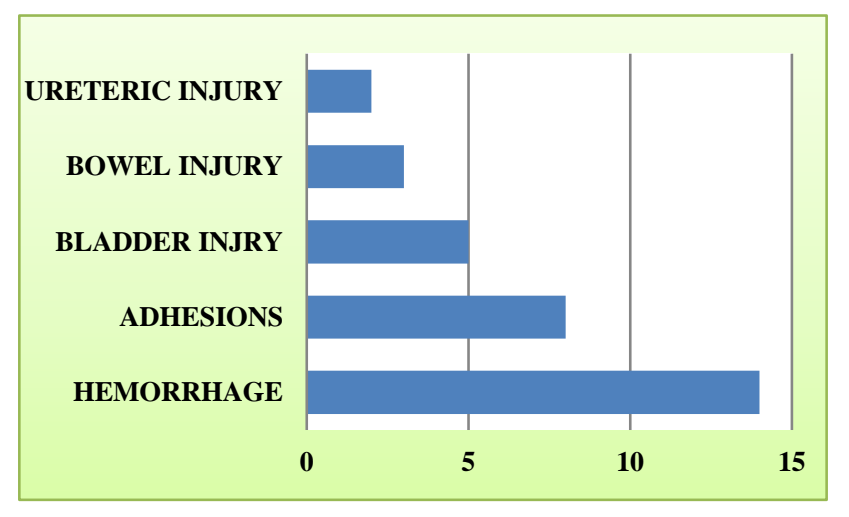

Figure 3: Reasons for conversion to laparotomy.

Conversion to laparotomy occurred in 32 out of 634 cases, 5.04\% (Figure 3). The most common reason for conversion to laparotomy was uncontrolled intraabdominal hemorrhage (14 out of 32 cases, $43.7 \%$ ), dense adhesions ( 8 out of 32 cases, $25 \%$ ) and visceral injuries.

Table 4: Incidence of postoperative complications.

\begin{tabular}{|lll|}
\hline $\begin{array}{l}\text { Postoperative } \\
\text { complications }\end{array}$ & Number & Percentage \\
\hline Port site complications & 6 & \\
\hline Abscess & 2 & 0.16 \\
\hline Dehiscence & 3 & \\
\hline Hernia & 1 & \\
\hline Pulmonary edema & 4 & 0.1 \\
\hline Deep vein thrombosis & 1 & 0.02 \\
\hline Surgical emphysema & 2 & 0.05 \\
\hline Total & 13 & 0.34 \\
\hline
\end{tabular}


Postoperative complications involved wound infection was rarely reported, making the incidence difficult to estimate. The majority of wound infection are handled successfully with expectant management, drainage and antibiotics.

Subcutaneous emphysema resulted from preperitoneal placement of insufflation needle and trocar. Subcutaneous emphysema is identified when a patient is found to have crepitus under the skin. It regresses within 2 days.

\section{DISCUSSION}

The use of laparoscopic surgery has grown steadily in the past decade, but the incidence of complications causes concern. Laparoscopic complications remain a major cause of morbidity. Despite advanced technology and experience. There are many studies of the complications of laparoscopy, but since most are retrospective, they may underestimate some of the complications that can occur.

Present study provides results on all types of laparoscopic procedures performed by experienced and inexperienced laparoscopic surgeons. The risk of complications is universally related to the training and experience of the surgeon. ${ }^{15}$ While the majority of surgical procedures are performed by gynecologists who received training and supervision in a formal resident training programme, a large group of surgeons who currently perform laparoscopic surgical procedures acquired their experience outside an approved resident training programme. The time taken to acquire sufficient experience in laparoscopic surgical techniques is long and the risk of complications is greatest early in the career of laparoscopic surgeons. Complications are likely to occur when new techniques are practiced, or new operating instruments are acquired.

Of 3724 laparoscopic procedures, 214 complications occurred $(5.8 \%$ of all procedures) and one death occurred. The complication rate was $0.31 \%$ for diagnostic laparoscopic procedures, $3.20 \%$ for sterilization and $1.96 \%$ for operative laparoscopy. Postoperative complication rate was $0.34 \%$. The frequency of major and minor complications according to present data (5.8\%) is slightly above the range of values reported in earlier studies, that is, between $0.2 \%$ and $3 \% .^{6,10-12}$

Johnston et al reported a rate of major complications of $0.6 \%$, considerably lower than present rate , a difference that may be due to the fact that patients in their study were treated at a center staffed by surgeons who were highly experienced in laparoscopic surgery (between 8 and 16 years of experience), and greater experience is a variable known to be closely related to lower percentage rates of complications. ${ }^{6}$ With time, laparoscopic procedures have become widely used at present center and present surgeons have acquired more experience. As a result, complex laparoscopic procedures have been performed more frequently. Complications are closely related to the level of difficulty of the operation: complex procedures had an 8-fold higher risk of serious complications and a 7-fold higher risk of minor complications compared with technically simple procedures. This finding is consistent with results published by Magrina, Chapron et al and Leonard et al. ${ }^{10,11}$ The likelihood of conversion and failed laparoscopy was also related to the level of technical difficulty.

Urinary bladder injury was the most common visceral complication in much of the literature, as well as in present series. It happened more commonly in TLH group because of the closeness of the bladder to the cervix and frequent history of cesarean sections. Fortunately; all patients were recognized during surgery and repaired by laparotomy or vaginally. Early recognition with an immediate repair procedure overcomes further sequelae.

Intestinal injuries were the second most common major visceral complications in this series. This incidence was reported between $0.06 \%$ to $0.65 \%$. In other large studies, bowel injuries accounted for approximately $20 \%$ of all complications and almost half of all major complications by laparoscopy. ${ }^{10,13}$ In this study, intestinal complications were seen in three cases accounting for $0.08 \%$. All of these complications were repaired by laparotomy. In injury to sigmoid colon patient received ileostomy and tube colostomy for first repair procedure followed by prolonged hospitalization (60days) with serious complications which resulted later in death due to sepsis.

Ureteral injuries in gynecologic laparoscopy usually are not recognized during surgery; only those patients with persistent abdominal or flank pain, abdominal distention, fever may raise the suspicion during postoperative phase. ${ }^{16}$ Once ureteral injury was detected in a late postoperative period after the formation of ureteral fistula, ascites with urine content might complicate the situation. Although present late recognized case was successfully repaired by ureteroscopy with double J ureteral stent without further incident. In present series ureteral injury rate $(0.05 \%, 2 / 3724)$ was less, as compared to general reported rate $(2.8 \%, 70 / 2491) .{ }^{17,18}$ The proximity of ureter to the uterosacral ligaments must be carefully managed during the manipulations in the related surgical field.

Inserting the trocars and creating pneumoperitoneum form part of laparoscopy and should not be considered "less important" techniques, given that a non-negligible percentage of complications can occur during these procedures. Occasionally, these complications can be dramatic as when a great vessel is damaged. ${ }^{19,20}$ Among the laparoscopies studied in this article, there was no great vessel injury (vena cava) during entry which was seen in other studies. 
The inferior epigastric vessels are the most commonly injured vessels often injured at the time of lateral trocar placement. These vessels should be identified laparoscopic ally and their course should be observed from the inguinal canal up along the anterior abdominal wall.

In a review of the literature, the overall rate of conversion to laparotomy was $2.1 \%$. The two most common reasons for conversion to laparotomy were major vascular and intestinal injuries. ${ }^{9}$ In the authors' experience, conversion to laparotomy rate in advanced operative cases was $5.04 \%$ and most common reasons were dense adhesions and uncontrolled intraabdominal hemorrhage.

Among the potential complications of general anesthetics are hypoventilation, esophageal intubation, gastroesophageal reflux, bronchospasm, hypotension, narcotic overdose, cardiac arrhythmias, and cardiac arrest. The head down (Trendelenburg's) position, in combination with the increased intraperitoneal pressure provided by pneumoperitoneum increase the incidence of complications related to general anesthesia. In this study these complications were not seen.

\section{CONCLUSION}

Laparoscopic surgery was a safe procedure in the cases authors analyzed at present center, but it is not without risks of serious complications, of which the surgeon should be aware. The popularity of minimally invasive surgery is increasing as the amount of laparoscopic procedures being performed daily is increasing. During the 5 years of this study, the complexity of procedures being performed also increased. The evaluation of the incidence and the type of complications in this series should be beneficial for developing proper skills as laparoscopic surgeons for future procedures performed.

\section{ACKNOWLEDGMENTS}

Authors would like to acknowledge Dr. G. S. Shekhawat, Professor and Head of Department, Obstetrics and Gynaecology, Smt. Kashibai Navale Medical College and General Hospital, Pune; Dr. Hemant Damle, Professor, Smt. Kashibai Navale Medical College and General Hospital, Pune and the entire faculty of Department of Obstetrics and Gynecology at SKNMCH and GH for their kind support and cooperation.

Funding: No funding sources Conflict of interest: None declared

Ethical approval: The study was approved by the Institutional Ethics Committee

\section{REFERENCES}

1. Hoffman CP, Kennedy J, Borschel L, Burchette R, Kidd A. Laparoscopic hysterectomy: the Kaiser
Permanente San Diego experience. J Minim Invasive Gynecol. 2005;12:16-24.

2. Alessandri F, Lijoi D, Mistrangelo E, Ferrero S, Ragni N. Randomized study of laparoscopic versus minilaparotomic myomectomy for uterine myomas. J Minim Invasive Gynecol. 2006;13:92-7.

3. Mais V, Ajossa S, Guerriero S, Mascia M, Solla E, Melis GB. Laparoscopic versus abdominal myomectomy (a prospective, randomized trial to evaluate benefits in early outcome). Am J Obstet Gynecol. 1996;174:654-8.

4. Murphy AA, Nager CW, Wujek JJ, Kettel LM, Torp VA, Chin HG. Operative laparoscopy versus laparotomy for the management of ectopic pregnancy: a prospective trial. Fertil Steril. 1992;57:1180-5.

5. Mariña Naveiro Fuentes AR, Rilo JC, Paredes AG, Romero MT, Parra JF. Complications of laparoscopic gynecologic surgery. JSLS. 2014;18(3).

6. Johnston K, Rosen D, Cario G, Chou D, Carlton M, Cooper $\mathrm{M}$, et al. Major complications arising from 1265 operative laparoscopic cases: a prospective review from a single center. J Minim Invasive Gynecol. 2007; 14:339-44.

7. Perino A, Cucinella G, Venezia R, Castelli A, Cittadini E. Total laparoscopic hysterectomy versus total abdominal hysterectomy: an assessment of the learning curve in a prospective randomized study. Hum Reprod. 1999;14:2996-9.

8. Sami Walid M, Heaton RL. Laparoscopy-tolaparotomy quotient in obstetrics and gynecology residency programs. Arch Gynecol Obstet. 2011;283:1027-31.

9. Magrina JF. Complications of laparoscopic surgery. Clin Obstet Gynecol. 2002;45(2):469-80.

10. Chapron C, Querleu D, Bruhat MA, Madelenat P, Fernandez H, Pierre F, et al. Surgical complications of diagnostic and operative gynaecological laparoscopy: a series of 29,966 cases. Hum Reprod. 1998; 13:867-72.

11. Leonard F, Lecuru F, Rizk E, Chasset S, Robin F, Taurelle R. Perioperative morbidity of gynecological laparoscopy. A prospective monocenter observational study. Acta Obstet Gynecol Scand. 2000;79:129-34.

12. Jansen FW, Kapiteyn K, Trimbos-Kemper $\mathrm{T}$, Hermans J, Trimbos JB. Complications of laparoscopy: a prospective multicentre observational study. Br J Obstet Gynaecol. 1997;104(5):595-600.

13. Härkki-Sirén P, Kurki T. A nationwide analysis of laparoscopic complications. Obstet Gynecol. 1997;89:108-12.

14. Guerra S, Marín JM, Cuesta MC, Martínez-Etayo M, Arina R, Lete I. Resultados de 1000 cirugías ginecológicas laparoscópicas sucesivas. Prog Obstet Ginecol. 2013;56:84-6.

15. Soderstrom RM, Butler JC. A critical evaluation of complications in laparoscopy. J Reprod Med. 1973;10:245-8. 
16. Gomel V, James C. Intraoperative management of ureteral injury during operative laparoscopy. Fertil Steril. 1991;55:416-9.

17. Ostrzenski A, Radolinski B, Ostrzenska KM. A review of laparoscopic ureteral injury in pelvic surgery. Obstet Gynecol Surv. 2003;58:794-9.

18. Donnez O, Donnez J. A series of 400 laparoscopic hysterectomies for benign disease: a single centre, single surgeon prospective study of complications confirming previous retrospective study. BJOG. 2010;117:752-5.

19. Ahmad G, Duffy JM, Watson AJ. Laparoscopic entry techniques and complications. Int J Gynaecol Obstet. 2007;99:52-5.
20. Vilos GA, Ternamian A, Dempster J, Laberge PY, The Society of Obstetricians and Gynaecologists of Canada. Laparoscopicentry: a review of techniques, technologies, and complications. J Obstet Gynaecol Can. 2007;29:433-65.

Cite this article as: Shastri SS, Singh AA, Darawade SP, Manwani SD. Complications of gynaecologic laparoscopy: an audit. Int J Reprod Contracept Obstet Gynecol 2018;7:4870-6. 